\title{
Introducing the paradox theory in logistics and SCM research - examples from a global sourcing context
}

Erik Sandberg

The self-archived version of this journal article is available at Linköping University Institutional Repository (DiVA):

http:/ / urn.kb.se/ resolve?urn=urn:nbn:se:liu:diva-139923

N.B.: When citing this work, cite the original publication.

This is an electronic version of an article published in:

Sandberg, E., (2017), Introducing the paradox theory in logistics and SCM research - examples from a global sourcing context, International Journal of Logistics, 20(5), 459-474. https:// doi.org/ 10.1080/ 13675567.2017.1280007

Original publication available at:

https:/ / doi.org/ 10.1080/ 13675567.2017.1280007

Copyright: Taylor \& Francis (Routledge): STM, Behavioural Science and Public Health Titles

http:// www.routledge.com/ 


\title{
Introducing the paradox theory in logistics and SCM research - Examples from a global sourcing context
}

This version is to be used for parallel publishing. This is the latest version of the article after peer-review but before the journal's formatting.

Author: Erik Sandberg, Linköping University

\begin{abstract}
The purpose of this paper is to introduce and explore the use of paradox theory in a logistics and SCM research context. Although logistics and SCM scholars as well as practitioners have been aware about the existence of paradoxes, they have so far lacked a more formal theoretical framework for further identification and classification of these. Framed in the four general paradox classes of learning, belonging, organising and performing, the paper outlines paradoxes inherent in the global sourcing practices of two case companies. The findings demonstrate the paradox theory to be a useful tool for a systematic illumination and classification of paradoxes valuable for practitioners, researchers as well as teachers in the domain of logistics and SCM. The paradox theory may also help to identify and emphasize inconsistencies among different research fields. This is particularly valuable for research areas built upon multiple research disciplines such as global sourcing. In conclusion, the paper suggests that the paradox theory offers a new lens through which an organisation could be better explored, described and understood.
\end{abstract}

Key words: paradox, theory development, case study, global sourcing

\section{Introduction}

The research field of logistics and supply chain management (SCM) has a strong tradition of borrowing theories from other disciplines (Stock, 1997; Defee et al., 2010; Halldorsson et al., 2015), and the advantages gained from the application of other theories are well established in the research community (Halldorsson et al., 2015; Defee et al., 2010). Thanks to complementary theories a broader, more multi-faceted picture of logistics and SCM that goes beyond traditional movements, storage and control issues has been established (Defee et al., 2010). As a research field, the boundaries to other disciplines are fluid (Halldorsson et al., 2015) and there is no such thing as "one unified theory" of logistics or SCM (Halldorsson et al., 2007). Rather, in the very centre of successful research in logistics and SCM stands continuous application and updating of complementary theories from other research fields. One such complementary theory, which has not yet been applied in a logistics context, is the paradox theory. 
The purpose of this paper is to introduce and explore the use of paradox theory in a logistics and SCM research context. The paradox theory stems from the organisational research field where it has been developed during the last two decades. A paradox could here be defined as "contradictory yet interrelated elements that exist simultaneously and persist over time" (Smith and Lewis, 2011, pp. 382). This definition emphasises that the underlying logic for each element may seem rational when dealt with separately, but appears to be inconsistent when contrasted against each other. The core message of the paradox theory is that in order to create an effective organisation (or a supply chain), paradoxes have to be managed both internally among functions and externally in the interface towards other supply chain members. Conflicting goals and strategies must continuously be balanced against each other such as the tensions between centralisation and decentralisation, control and flexibility, and global and local. By focusing on these tensions, management becomes aware of their impact on company performance and can even exploit them as a driver for organisational development (Graetz and Smith, 2009).

The existence of tensions among different goals and strategies is not new in a logistics and SCM context. Particularly the notion of trade-offs has been well acknowledged among scholars as well as practitioners for a long time. However, these trade-offs are mainly limited to tensions regarding operational performance in the physical flow of goods, typically cost vs. lead time considerations (e.g. Lowson, 2001; Christopher et al., 2006). Except for these trade-offs (referred to as "performing paradoxes" later on in this paper) there are also other, more strategically oriented types of paradoxes that have received considerably less attention in logistics and SCM research. So far, logistics researchers have lacked a more formal theoretical framework for the further identification and classification of these. As will be demonstrated in this research, paradox theory offers (for researchers, practitioners as well as teachers) a new lens through which an organisation could be better explored, described and understood.

In order to explore the applicability of the paradox perspective in a logistics and SCM setting, this paper applies a generic framework of paradoxes on two case companies' global sourcing practices. Global sourcing is commonly defined as "an advanced approach to sourcing and supply management that involves integrating and coordinating common materials, processes, designs, technologies and suppliers across worldwide buying, design and operating locations" (Trent and Monczka, 2005, p 24). Global sourcing has become a strategic matter for many companies as a means to deliver superior value that can be sustained over time (Ganesan et al., 2009; Paché, 1998; Gelderman and Semeijn, 2006; Quintens et al., 2005). However, global sourcing represents extensive challenges (Bygballe et al., 2012; Paché, 1998; Trautmann et al., 2009), and to reap the benefits of global sourcing, such as lower total costs and access to raw material, companies typically struggle with extended supply chains with more parties involved, increased and unpredictable lead times, cultural differences, safety and supply chain risk issues, and deficiencies in delivery information (Monczka et al., 2010: Christopher et al., 2006). In this dynamic and challenging environment, sourcing practitioners as well as researchers face numerous paradoxes, sometimes explicitly stated and sometimes hidden in the organisation or the supply chain. Therefore, in order to explore the applicability of the paradox theory in logistics and SCM research, the area of global sourcing is a suitable one.

The remainder of this article continues with methodology and some general information about the two case companies; a Swedish retail company that operates mainly in the clothing fashion industry, and a Swedish wholesale company selling workwear clothing 
and associated products. Together, these two case companies function as showcases for paradoxes present in a global sourcing environment. Thereafter the essence of the paradox theory is presented in a global sourcing context and exemplified through the case studies. The structure follows a framework of four general theoretically derived paradox classes of learning, belonging, organising and performing. The final section discusses the use of paradox theory in logistics and SCM research and addresses a number of future research themes.

\section{Methodology}

In order to explore the paradox theory in a logistics and SCM context, relevant literature on paradoxes and global sourcing has been reviewed and summarised in a narrative approach (Paré et al., 2015). The body of paradox literature is rapidly growing, but is still to be considered as immature and fragmented (Smith and Lewis, 2011). Terms such as paradoxes, dualities, dilemmas and dichotomies are often referred to in a vague sense, and few literature reviews that consolidate the research topic exist. One exception is however Smith and Lewis (2011), who, based on previous classifications made by one of the authors (Lewis, 2000; Luscher and Lewis, 2008), present a comprehensive overview and categorisation of existing paradox classes. This framework, including the four generic classes of paradoxes related to learning, belonging, organising, and performing, was applied in this research as a tool to structure and explore paradoxes in global sourcing research.

Two case studies based on an inductive, qualitative research approach (Pratt, 2009) have been conducted as a means to further exemplify paradoxes inherent in global sourcing practices. The two case studies were conducted during 2013-2015. These companies have, together with two other companies, previously participated in a global sourcing research project conducted by the author. During this project the two case companies distinguished themselves from the others due to their awareness of paradoxes present in their organisations and a conscious search for how to deal with these. A rich, informative body of data related to paradoxes was thus identified in the companies and therefore they are considered suitable case companies (Flyvbjerg, 2006; Eisenhardt and Graebner, 2007).

The unit of analysis has been the case companies' global sourcing practices. Without own production, dealing with commodity goods, global sourcing becomes vital for competition and a major task for a majority of functions in the companies. Logistics and purchasing, but also marketing and sales are all actively involved in the companies' global sourcing practices. When all these functions participate a majority of the companies' different strategies and goals become represented and linked to the global sourcing practices. The two selected companies are also, despite the representation of many functions involved, still relatively small in number of employees, which makes identification of possible tensions, strategies and goals easier to understand and grasp as an outside researcher.

In total, eight semi-structured interviews (Yin, 2003) have been conducted with the case companies for the purpose of this research. In company A interviews were held with managing director, the logistics manager, the purchasing manager and a controller. At company B the informants were the supply chain manager, the demand chain manager, a purchaser, and a warehouse manager. Due to slightly different internal organisations, 
the titles of the informants differ between the companies. Although the total number of people interviewed may be small, the four selected people at each company provided satisfactory understanding of the companies' paradoxes. All interviews were conducted face-to-face with the author of this paper and lasted between 1,5-2 hours. Although slightly adjusted to fit the actual informant, all interviews followed a general interview guide including the three general areas of (1) supplier selection parameters, (2) design of physical flow of goods, and (3) sourcing organisation. At the beginning of the interviews the concept of paradoxes was explicitly presented to the interviewees and during the interviews they were encouraged to reflect upon paradoxes present in their global sourcing practices.

In addition to the eight interviews focused around paradoxes, the author has had access to a large amount of other data sources about the companies, gathered during the larger research project in which the two companies participated. These sources include other interviews (not focused on paradoxes but covering issues such as business models, distribution, etc.), a workshop about future sourcing challenges, logistics-related consultancy reports, and other internal documents. The role of these other data sources has been to enhance the researcher's understanding of each case company's sourcing practices and enable improved, more precise discussion on the paradoxes inherent in these practices.

The researcher transcribed all eight interviews. A general report on the findings was also written as a means to gather and structure pieces of information from the interviews. The report, as well as an earlier version of this paper, has been distributed to the informants in order to ensure research validity. The reporting and the analysis have followed the four paradox classes of learning, belonging, organising and performing. The analysis can be described as an iterative process in two steps. First, based on the four paradox classes, global sourcing literature has been reviewed and paradoxes identified. Second, examples of paradoxes from the case companies have been extracted. This was achieved primarily by colouring the transcriptions of the interviews and identification of power quotes that were used to provide details and illustrate key points in the cases (Fawcett et al., 2014). The objective of the analysis has not been to produce an exhaustive list of all paradoxes present in global sourcing. Rather, the guiding principle has been the search for clear examples of paradoxes that are easily understood and relevant for the targeted audience of logistics and SCM researchers.

\section{About the case companies}

\subsection{Company $A$}

Case company A is a family-owned Swedish retailer that provides women's fashion and orientally inspired furniture. The company operates about 100 stores with in total about 700 employees in Sweden, Denmark, Norway and Iceland and has a turnover of about 100 Million Euro. About 55-60 people work at the headquarters in Stockholm, Sweden, of which the purchasing department has about 30 employees, including 6 purchasers, purchase assistants, quality managers, etc.

As a major part of the business model, and due to historical reasons, the company relies heavily on strong relationships with a number of Indian suppliers. The Swedish owner family established a relationship with an Indian business family 50 years ago; this 
remains an important partner for the company today, now in the second generation. This Indian supplier has been joined by several others and today, in terms of purchasing expertise, the company knows the Indian supplier market very well. It has about 35 people employed in India in two local purchasing offices and a distribution centre in Mumbai, through which all Indian good are sent on to the central warehouse in Sweden. In order to push as much administration and goods handling as possible backwards in the supply chain, goods coming from India are to a great extent packaged to individual stores already in India. Overall, the two purchasing offices are considered the extended arm of the Swedish purchasing department, taking care of all local operational contacts with suppliers, including quality control, deliveries and administration. The local purchasing offices have also become an important partner for price negotiations, supplier- development and selection.

Beside Indian suppliers, representing about $60 \%$ of total supply of goods, the case company also source from China (stands for about 30\% of the total supply) and European countries (in particular Turkey). The expansion of sourcing regions is mainly due to increased awareness of quality demands, limited production capacity among the Indian suppliers, and a need for decreased lead times, but also price.

\subsection{Company $B$}

Company B belongs to a Swedish investment company listed on the Stockholm stock exchange market. The focus for this research is the sourcing function of a wholesale subsidiary (here labelled company B) that sells workwear fashion in a number of European markets. In addition to headquarters in Sweden, company B has a factory in Latvia and a central warehouse in Poland, operated by a logistics provider. About 80 employees report to the supply chain manager, head of the company's sourcing function. As well as traditional tasks such as purchasing, demand planning, quality, CSR etc, this function also includes the factory in Latvia (about 50 employees), sales support and people employed in Asia.

Case company B has undergone a development from domestic, to international (European suppliers), to global sourcing. The factory in Latvia is today mainly used for development, testing and special series production in smaller scale, representing about $2 \%$ of the total sales volume. Major contemporary supplier regions are Vietnam and Bangladesh, where finished items as well as raw material (textiles) are procured. In total, the company has about 50 suppliers, of which the majority are based on long term, collaborative relationships. Except for contact with purchasers and other staff at the headquarters in Sweden, operational concerns are facilitated mainly by three regional operation managers placed in Asia, and a minor purchasing office in Vietnam. All goods are brought from the Asian suppliers to the central warehouse in Poland by boat, and thereafter transported by truck to the regional sales markets around Europe.

\section{Paradoxes in global sourcing}

Although a commonly used term, "paradox" has so far been applied with a vague sense in logistics research. In the organisational research, however, a particular "theory", or "perspective" of paradoxes has been developed in recent years that calls for a renewed 
understanding for how to manage contradictions and tensions within an organisation (Dameron and Torset, 2014). Although other terms have been applied, such as dualitytheory (Evans et al., 2002; Graetz and Smith, 2009) or ambidexterity theory (Nosella et al., 2012), paradox theory is the most commonly applied name of this research stream. In short, Smith and Lewis (2011) argue that organisational research has undergone three major development stages, where the earliest research generation opted for an answer to the question "Is A or B the most effective way?", thus assuming that one organisational design is always superior to other alternatives. Thereafter the next generation of research, which was developed during the 1960s instead asked "Under what conditions is A or B the most effective way?". This stream of literature has been labelled contingency theory and has been applied relatively often in logistics research during the years, perhaps most frequently when combined with the strategy-structureperformance paradigm (Stock et al., 1998).

A third, paradox-based development stage focuses on tensions and conflicting goals inherent within and between elements in an organisation or supply chain. The basis for this theoretical perspective was developed during the 1980s as a new means to capture and understand the underlying logic for effective organisations, particularly in times of rapid change (Evans et al., 2002; Graetz and Smith, 2009). Whereas some tensions could be resolved by simply choosing one of the two opposed arguments (an either/or choice referred to as a "dilemma") others could be avoided by finding a solution that integrates the two sides (referred to as a "dialectic") (Smith and Lewis, 2011). However, some tensions, here referred to as paradoxes, should not be resolved or avoided, instead they should be managed within the organisation. A paradox theory does not advocate the search for an optimum "position" among the tensions, or their settlement or avoidance. Rather, it advocates an act of balance of the tensions on a continuous basis in line with a turbulent environment (Nosella et al., 2012; Smith and Lewis, 2011; Poole and Van De Ven, 1989). In fact, such a perspective goes even further and does not only recognise the tensions, but also exploits and encourages the creativity and dynamism enhanced by the presence of tensions (Graetz and Smith, 2009; Poole and Van de Ven, 1989; Dameron and Torset, 2014; Lewis, 2000). Thus, tensions should be allowed to co-exist in the organisation, as these tensions could be seen as an important driving force for innovation and development (Galunic and Eisenhardt, 2001; Eisenhardt, 2000; Graetz and Smith, 2009; Lewis, 2000).

Managing paradoxes - or coping as has been suggested as a better term for handling paradoxes in an organisation (Handy, 1994) - has been recognised as a challenging task (Seo et al., 2004; Lewis, 2000). It requires a leadership that explores, rather than suppresses the tensions (Lewis, 2000). A first, major task becomes to make paradoxes explicit through "paradox cognition" (Smith and Lewis, 2011; Graetz and Smith, 2009) as many paradoxes are latent until conditions such as scarcity of resources make them explicit to management. This can be made by adopting what Graetz and Smith (2009) labels a "dualities aware perspective". Helpfully, Smith and Lewis (2011) identified four generic categories of paradoxes that are applied in this paper as a means to structure our analysis of paradoxes, and help to establish such a "dualities-aware perspective". The subsequent sections therefore, based on the Smith and Lewis framework, develop global sourcing-related paradoxes in the four categories of (1) Learning, (2) Belonging, (3) Organising, and (4) Performing. 


\subsection{Learning paradoxes}

Learning paradoxes arise under efforts to adjust, renew, and change an organisation, as they foster tensions between destroying past understandings to create new, future practices (Smith and Lewis, 2011; Lewis, 2000), i.e. historical experiences and knowhow is continuously challenged in the organisation by new ideas and knowledge. Learning in a wide sense, including processes of knowledge creation and innovation is of fundamental importance for future success, and the case studies presented in this research clearly demonstrate this. Overall, the clothing industry has undergone major changes in recent years due to worldwide globalisation with increased competition and the resulting need for more rapid change and continuous learning. Of particular interest in the case companies is learning in the areas of new technology and materials, and sustainability improvements.

The learning paradoxes are, in these cases, particularly well framed in the act of balance between learning inside a collaborative, long term relationship, and at the same time the acquisition of new knowledge and innovation through new relationships (Jonsson and Tolstoy, 2014). Long-term relationships may facilitate development and trust-based interorganisational learning, but at the same time too long relationships may jeopardise innovation and new thinking in the supply chain.

From a paradox perspective, literature on global sourcing brings forward arguments for both sides of the coin. Whereas global sourcing articles based upon a supply chain management (SCM) tradition promote long term, stable relationships to be a facilitator of learning, innovation and development (Mentzer et al., 2001; Brito et al., 2008; Åkesson et al., 2007), other research streams instead bring forward the advantages of new supplier constellations. For instance, in the economic geography literature, a dynamic view on sourcing relationships is taken, pointing out that the most appropriate supplier as well as sourcing region may shift over time (e.g. Toklati, 2008; Gibbon, 2002). Altering market requirements changes the needs of the buying company, which may drive a shift in the selection of sourcing region as well as individual suppliers. The ability to exploit local opportunities in the region and at the supplier is decisive for competitiveness (Kotabe and Murray, 2004), and if these opportunities change, the supplier base may also need to be changed.

\section{Examples from the cases}

When considering the case companies, a fundamental part of company A's business model are the long term relationships with (above all) their Indian suppliers, but also some Chinese suppliers. Through stable, long term collaboration, some relationships more than 50 years old and based on an SCM philosophy, company A ensures learning and innovation together with their suppliers. According to company $\mathrm{A}$, the long term view enables the suppliers to get to know company $A$, and what their customers want:

"It is important that the suppliers understand what our company and our customers want. We got this confirmed at the beginning of this year when we conducted a major review together with our suppliers of what we really wanted from them: It was our older, most long term suppliers that were able to present the best, most suitable products. They simply knew what we wanted, even in cases where our demands were more vague and built upon 
feelings rather than hard-based facts. This difference became very clear between our old and new suppliers."

\section{(Purchasing Manager, Company A, author's translation)}

Interviewees at Company A also hold their long term relationships as the main reason for their successful sustainability work, an area that is in continuous need for learning and development. Collaboration and SCM practices are expected to improve CSR and environmental issues beyond traditional control activities. For example, trust and long term planning in the relationships with ten Indian fashion manufacturers have enabled them, together with company A, to invest in, and construct a new area of adjacent production units with a shared efficient water cleaning facility. The case company proudly present these Indian relationships and considers them to be strategically important and part of the company's success. These enhancements, the company CEO argues, would not have been possible without long term, trust-based relationships that enables improved dialogue and learning beyond simplified requirements specified in for instance formal code of conduct agreements and other control activities.

"It is no quick-fix to work with CSR-issues. It takes many, many years of hard work to create fair working conditions."

(CEO, Company A, author's translation)

Whereas long term collaborative relationships are considered to be crucial for company learning and development, the interviewees also recognise new supplier relationships as an enabler for improved learning. One example of this is when company A decreased their business with some Indian suppliers of tricot and instead procured these products from new suppliers in Turkey. These new relationships turned out to be less costly than expected, and supported the company with new knowledge in production and materials, thus "destroying past understandings and creating new, future practices" as discussed by Smith and Lewis (2011). Experiences from the new suppliers in Turkey also improved the relationships with existing suppliers back in India. New knowledge and demands were brought on to the agenda, shaping the performance of the old suppliers. Overall, as a strategy for enhancing learning and making the most out of wellfunctioning existing long-term relationships, and at the same time assuring new thinking and new influences from other suppliers, company A has started to develop a more diverse view on their sourcing philosophy:

"Today we try to avoid too much of dependence towards some of our suppliers. We have employed more suppliers in these critical areas, and have created a kind of healthy anxiety among them. They [now] realise that they will have to deliver each and every time... The relationship is very important for us, but the supplier must never take us for granted. There are always other suppliers out there who can deliver just as good [as they]."

(CEO, Company A, author's translation) 
Similarly to company A, company B has also adopted a sourcing strategy that relies on a number of long term stable supplier relationships. The collaborative atmosphere in the supplier relationships is considered important for a number of reasons such as access, i.e. be given priority in the production planning, but also for reasons such as joint development. Company B has a market position built on high-end brands, which makes continuous learning even more crucial. Although learning is enhanced partly in-house through their own factory in Latvia, long term stable relationships with a number of skilled suppliers is a fundamental strategy for learning and innovation in the company.

On the downside of long term supplier relationships, there is a risk that the pace of learning and innovation may decrease, as a result of too much routine and an unwillingness to think innovatively. As noted by the Demand Chain Planner, and in line with the learning paradox, the length of the relationships hence becomes an act of balance:

"There must be a balance. It [long term relationships] requires that they [the suppliers] also are active and update themselves and what they are doing. And we must also get new blood into our company. So the combination of the long, stable relationships and the new ones is important, i.e. to have a mix."

(Demand Chain Planner, Company B, author's translation)

\subsection{Belonging paradoxes}

Belonging paradoxes are related to the issue of identity in the organisation (and the supply chain as focused in a global sourcing setting), which typically "fosters tensions between the individual and the collective and between competing values, roles, and memberships" (Smith and Lewis, 2011, p. 383). A complex, world-wide supply chain with multiple participants, diverse cultural backgrounds and different supply chain strategies has been recognised as a challenging task to manage for most sourcing organisations (Ganesan et al., 2009). One issue of particular interest for managing relationships in the supply chain is the use of intermediaries, whose role is to coordinate the supply chain in an effective and efficient way (Gibbon, 2002). Intermediaries such as buying offices or agents represent challenges related to the belonging paradox as they become squeezed between the local suppliers in the region and the buying department at the headquarters. Different understandings, information and lack of communicated strategies and policies may result in conflicting interests and cause behavioural uncertainty (Paché, 1998).

From a belonging perspective, the use of intermediaries becomes an act of balance between encouraging them to plan and act as independent units on the one hand, and at the same time create a sense of common goals and values for the supply chain as a whole. In a global sourcing context, the need for a proper "belonging-balance" is mainly driven by the fact that worldwide supply chains include challenges related to cultural differences. A global supply chain, in comparison to a domestic one, naturally creates more tensions in buyer-supplier relationships as there are greater cultural and regulatory differences that need to be tackled (Cho and Kang, 2001). To function properly, a certain degree of freedom and local focus is needed in order to handle these cultural differences. On the other hand, cultural differences that are too great between 
e.g. a local purchasing office in the Far East and the head quarters in Europe may jeopardise effectiveness and efficiency in the supply chain.

\section{Examples from the cases}

An extension of the supply chain together with communication barriers (time differences and language) means that intermediaries such as local buying offices (as in the case company A) or regional operations managers (as in company B) play an important role in the case companies' supply chains. The use of these intermediaries is above all considered as a strategy to come closer to the suppliers, and create controllable and trust-based long term relationships. However, the intermediaries constitute a belonging paradox, as they are also seen as an extension of the supply chain that may hamper cultural understandings between head quarters and suppliers. To work as a united company, with one message and one strategy, communication and information sharing in the supply chain becomes more demanding.

In company $\mathrm{A}$, from the headquarters point of view, the local buying offices in India function as an extended arm of the headquarters, involved in suppliers' production, price negotiations, logistics operations, etc. The interviewees (placed at the headquarters in Sweden) consider the two local purchasing offices as a means of getting closer to the suppliers, enabling local presence and in-depth understanding of supplier conditions. The local purchasing offices handle the price negotiations and provide headquarters with insights into the actual production costs that have enabled the company to negotiate better purchasing prices. However, giving more responsibility and control to the local purchasing offices also increases the distance to the headquarters. The more autonomy is held by the local office, the more risk there is to headquarters in terms of knowledge loss, and correct understanding of headquarters' plans and strategies.

"Yes, even though we of course consider the purchasing office as beneficial for us, there is a paradox here... we of course want their complete loyalty [towards the head quarters] and at the same time we want them [the purchasing office] to act independent and take own initiatives."

\section{(Controller, Company A, author's translation)}

Company B faces a similar challenge in terms of their regional operations managers. In total, company B has three such persons situated in different regions in Asia, responsible for facilitating smooth supplier contacts, ensuring that delivery schedules are held, and that quality and sustainability issues are satisfactory. Framed in cultural as well as information sharing challenges, the regional operations managers play an important role as middlemen between the headquarters in Sweden and the suppliers in Asia. As in company $\mathrm{A}$, the challenge becomes to find a balance between control and guiding principles from headquarters on the one hand, and at the same time foster individual, local initiatives by the operations managers: 
"They [the regional operations managers] have [the understanding for] the culture. They know how it works. Sometimes we perhaps push them too hard. They mean let us handle this, we know how to deal with it."

(Purchaser, Company B, author's translation)

In a similar vein, the supply chain manager at Company B concludes:

"I think there must be some kind of general responsibility from the head quarters [for operations in the supply chain]. The strategy must come from here, both regarding our supply chain structure and the product range we are selling. Both these things give the frames for how we work regionally. However, at the same time individual initiatives needs to be taken. But there must be some kind of constraints framing the business."

(Supply Chain Manager, Company B, author's translation)

\subsection{Organising paradoxes}

Organising paradoxes arise when structuring the organisation, and include conflicts between attributes such as commitment, trust and creativity on the one hand, and efficiency, discipline and order on the other hand (Lewis, 2000). Typical paradoxes discussed are collaboration vs competition, empowerment vs direction, and control vs flexibility (Smith and Lewis, 2011). In a global sourcing setting, organising paradoxes have been acknowledged when discussing the design of the physical flow of goods from the sourcing region(s) (e.g. Asia) to the domestic markets (e.g. Europe or USA). For instance, Bygballe et al. (2012) outline four general retail supply chain structures from Asian suppliers to retail stores in Norway. These are (1) Deliveries between individual producers and retail stores, (2) Consolidation of shipments in the customer country, (3) Consolidation of shipments in the supplier country, and (4) Consolidation in both countries. Pros and cons in terms of e.g. control and flexibility are presented based on these four structures, which clearly demonstrates the presence of tensions and conflicting goals between the different alternative structures.

The organising paradox is closely related to the degree of collaboration (Mena et al., 2009) between the buyer and supplier, in which the advantages of close collaboration are compared against the advantages of having an arms-length, transaction-based relationship. Literature suggests a number of more specific aspects to consider when selecting degree of collaboration where organising paradoxes are in focus. For instance, Aastrup et al. (2007) highlights the many advantages and sacrifices caused by moving to closer category management collaboration in a retailer-supplier relationship. The authors claim that closer but fewer supplier collaborations concerning category management render many advantages in terms of e.g. continuous improvements, but also sacrifices in terms of increased dependency on the suppliers. Thus, the retailer has to weigh improved category management against loss of category control and negotiation power (Aastrup et al., 2007).

In addition to degree of collaboration, organising paradoxes are also due to vertical integration, i.e. to what extent the buying company owns the supplier. Åkesson et al. (2007) elaborate three major supply chain structures: (1) internal sourcing where the 
supplier/manufacturer is owned or partly owned by the buying company, (2) direct external sourcing where the buying company purchases goods from an independent supplier/manufacturer without the help of intermediaries, and (3) indirect external sourcing through trusted locally oriented intermediaries or agents. Overall, the different opportunities for the supply chain structure could be placed on a continuum between the extremes of a pure "market mode" where an external part handles all tasks of purchasing and management of supply on the one side, and a wholly owned manufacturing subsidiary on the other (Cho, 2009). To place the company at the right point on the continuum becomes one of the major management tasks of global sourcing.

From a paradox perspective, management has to balance different advantages and disadvantages with more or less vertical integration. Typical arguments for increased vertical integration are improved control, reduced uncertainty and ability to create pressure directly on the suppliers. Vertical integration also often leaves greater opportunities for development of, for instance, the product assortment (Paché, 1998), and facilitates exploitation of economies of scale (Cho, 2009). The downside of vertical integration is above all related to the need for stable, long-term volumes that could be problematic to warrant, in particular in a dynamic global environment. As a result of investments made, vertical ownership may hamper supply chain flexibility, for instance it may limit the company's ability to change supplier and supplier region (Cho, 2009).

\section{Examples from the cases}

Both company A and B struggle on a continuous basis with organising paradoxes related to degree of collaboration as well as degree of vertical integration. As argued in the section above, the degree of collaboration is in general high in both companies' supply chains. From an organising paradox point of view, collaboration is an instrument to improve control. For instance, collaboration is considered by both companies to be an important strategy for acquiring information, securing deliveries and improving lead times. In addition, collaboration is seen as a strategy for increased control of CSR-related issues. On the downside of a high degree of collaboration, the case companies mention high supplier dependency, which may reduce their flexibility. A too high degree of collaboration may cause a lock-in effect, where production, product range decisions, and new logistics solutions (e.g. new delivery routes, new third party logistics providers) are impeded.

To ensure control through collaboration, but at the same time avoid too high dependency on a specific supplier, company B holds the balance and continuity in existing supplier relationships as important, where neither too much, nor too little business reliance is placed on each supplier:

"In a well-functioning relationship it is important to treat this relationship in a good manner and not reduce, nor place too much business [on this supplier]. To provide a balance and thus become an attractive customer to the suppliers you want to work with is important."

\section{(Demand Chain Planner, Company B, author's translation)}


When it comes to degree of vertical integration, both companies acknowledge the relatively high investment costs for vertical integration as a main argument for not having their own production units in the Far East. In particular company B is well aware of the challenges as well as advantages related to vertical integration, as the company owns a factory in Latvia. Although small, and at its current state not influential on the total volumes, the purchasers at the headquarters need to assure a smooth production planning for this factory, although it sometimes could be several times more expensive in comparison to production in e.g. Vietnam. The positive effects of having the Latvian factory is however also very clear for the headquarters. The presence of capacity in the factory warrants a buffer for unforeseen problems with delayed deliveries and quality issues, hence increasing the flexibility of the company's deliveries. Also, in case of small volumes and special items, it could also be more profitable (in terms of total costs) to produce in the Latvian factory (due to lower total logistics costs).

\subsection{Performing paradoxes}

Performing paradoxes includes a discussion on "multiple and competing goals as stakeholders seek divergent organisational success" (Smith and Lewis, 2011, p. 383). The performance of global sourcing in terms of costs, lead times and services, but also sustainability issues, has been a dominating theme in global sourcing literature in the recent decade (e.g. Trent and Monczka, 2003; Christopher et al., 2006; Toklati, 2008; Gibbon, 2002; Åkesson et al., 2007; Jonsson and Tolstoy, 2014). In line with paradox theory, performance indicators such as costs, service, and lead times have been compared against each other and presented as trade-offs, dilemmas or similar (Christopher et al., 2006; Trent and Monczka, 2003).

To structure the existing literature, there are at least three major classes of performing paradoxes discussed in the global sourcing literature; (1) supply chain costs vs price, (2) the total costs vs service aspects, including lead times, and (3) "traditional" logistics performance measurements of cost and service vs sustainability performance (e.g. CO2emmisions or CSR-issues).

First, starting with cost- and price related paradoxes, it is a well-known statement in existing global sourcing literature that not only price should be considered, but the total costs of purchasing. A long row of "hidden costs" (costs difficult to identify and/or quantify) and "inflexibility costs" (costs related to a company's ability to cope with uncertainty) must be taken into consideration for a proper supply chain calculation (Lowson, 2001; Joo et al., 2010; Cho and Kang, 2001; Bygballe et al., 2012).

Second, in addition to the challenge of getting control of the total costs, the conflict between costs and service has for a long time been acknowledged as a key challenge for logistics in general (e.g. Bygballe et al., 2012; Gelderman and Semeijn, 2006; Trent and Monczka, 2003; Gibbon, 2002; Cho and Kang, 2001). Performance in terms of costs and service in the supply chain must be balanced. This balance not only concerns the buying company's organisation, but also other members of the supply chain. For instance, Bakal and Geunes (2010) point out that the carrying of inventory in the supply chain may cause a cost- and service-based conflict between retailers and their suppliers. Retailers often prefer late ordering as a means to avoid demand uncertainty and inventory speculation, in particular in seasonal products. At the same time, suppliers prefer longer lead times in order to better optimise and manage production capacities (Bakal and 
Geunes, 2010; Agrawal et al., 2002). The order timing therefore becomes an act of balance between avoidance of surplus inventory at the retailer and the supplier.

Third, global sourcing literature also claims that supply chain performance can not only be evaluated based on traditional logistics performance metrics such as total costs, service and lead time. Environmental and sustainability issues must also be considered in depth (Brito et al., 2008; Robinson, 2010; Hughes et al., 2007; Joo et al., 2010). Therefore, the attention to CSR aspects in literature has grown in recent years (Jonsson and Tolstoy, 2014; Robinson, 2010) and has received increased attention from many buying companies, in particular retail companies (Ganesan et al., 2009; Perry and Towers, 2013; Mamic, 2005). Due to market considerations such as brand image and customer attitudes, CSR and environment issues nowadays play a decisive role for many retailers in their selection of sourcing area and supplier (Ganesan et al., 2009; Perry and Towers, 2013; Robinson, 2010; Mamic, 2005).

\section{Examples from the cases}

In both case companies the interviewees are well aware of the three types of performing paradoxes presented above. Of particular interest in both companies is the tension between total costs on the one hand, and service performance in the form of lead times on the other. For the global sourcing operations in general this conflict of interest (the achievement of low total costs with short lead times), is one of the most prominent challenges that is measured and given management attention on a continuous basis in the case companies. This paradox has also been the driver for development and improved supply chain design. For instance, both companies have increased their efforts in making correct forecasts and improved supplier contacts through local purchasing offices (company A) and regional operations managers (company B). A common goal for these efforts has been to reduce unforeseen delays and thereby avoid prolonged lead times.

"Well, a general paradox... is of course our leadtimes vs our costs. This is something we work with all the time and is one of our key challenges."

(Logistics Manager, Company A, author's translation)

In addition, company $\mathrm{B}$ has also started to investigate European supplier alternatives, as a means to better handle the performance tension between total costs and lead times. As part of this work, total cost analysis for a potential European supplier has been conducted and compared to an existing one in Vietnam. In terms of lead time reduction, the benefits are obviously significant. Interestingly, total cost calculations also indicate that even though Vietnam supplier still is less costly, the difference is not as great as could be expected. The major reason for this is the reduced tied-up capital in the case of the European supplier. When taking the expected pace of monetary inflation into account over the next few years, the European supplier alternative becomes even more tempting. From a performing paradox point of view, the tension between total costs and lead times will not disappear if the company contracts the European supplier, but can be seen as a driver for new, improved sourcing practices. Thus, this is an example of how paradoxes drive development of the global sourcing practices. 
Another crucial paradox discussed in the literature and observed in the case companies is the tension between total costs and CSR performance. Both case companies are taking challenges related to CSR very seriously and cost calculations, e.g. evaluations of new supplier alternatives, are therefore always linked to a careful CSR evaluation. For instance, company A decided a couple of years ago not to source from Bangladesh due to insufficient knowledge of that sourcing region, although the total cost calculation indicated this as a very tempting alternative.

"We are definitely considering other sourcing regions. For instance, a few years ago we hired a new purchasing manager from H\&M and as a result we looked at opportunities in Bangladesh. However, today we can with pride say that we decided not to go on with Bangladesh since our CSR manager wasn't completely comfortable with that choice. CSRquestions are important for us and therefore she [the CSR manager] is able to stop our plans for entrance in a new region."

(Logistics Manager, Company A, author's translation)

Overall, performing paradoxes occur in a variety of ways in the case companies and are in general considered as something that has to be handled on a continuous basis. Several of the interviewees in both case companies witnessed a continuous internal dialogue and struggle where different interests were relatively well-known to involved parties. For instance, company A experiences continuous tensions regarding different performance measurements and has to deal with a continuous interest conflict between involved sourcing functions, in particular between (1) the gross profit margins driven by the controllers, (2) the fashion in terms of testing new, innovative products driven by the designers, and (3) possible, reliable supplier performance driven by the purchasers. In company A these three functions together have a continuous struggle to match their different interests. However, in line with paradox theory, these continuous negotiations are seen as something positive by the interviewees, that drive development and the need for finding new supplier solutions.

\section{Discussion and further research}

This paper has introduced and explored the use of paradox theory in a logistics and SCM research context. Framed in the four general paradox classes of learning, belonging, organising and performing, the previous sections outlined some of the most important global sourcing-related paradoxes identified in literature and the cases. The paper and its findings initiate a discussion about the applicability and use of paradox theory in logistics and SCM research. In the light of the findings from previous sections paradox theory appears to be a promising contribution from organisational theories into the logistics and SCM research field. There are in particular two research implications from this study.

First, the paradox theory plays an important role for the illumination and classification of paradoxes present in the organisation that could be valuable for practitioners, researchers as well as teachers in the domain of logistics and SCM. Although many paradoxes may be sensed and identified in a random and ad hoc manner, a paradox 
framework such as the one from Smith and Lewis (2011) offers a structured tool for further analysis in which a more exhaustive list of paradoxes that goes beyond the more obvious ones can be created. In addition, paradox theory has been shown to be a useful platform for a dialogue rather than a traditional interview between the researcher and the informant. The fundamental ideas of the paradox theory are relatively easy to comprehend and have in the empirical data collection been explained to the informants, making them more aware of the researchers' purpose and questions posed. As a result, more "hidden" paradoxes have been discovered. A clear statement about involved paradoxes may also advance and improve the information given by the informants that goes beyond pure identification of the paradoxes. Identification and discussion on paradoxes may enable a first, necessary understanding for the organisation, and a stepping-stone for more specific information about the company's behaviour and decisions. During almost every interview, the informant reasoned in accordance with the following: "We have a paradox that consists of an interest conflict between $\mathrm{X}$ and $\mathrm{Y}$. That is the reason we have...". For instance, the belonging paradox of the buying offices in company A explains their substantial efforts to increase transparency from the headquarters, via buying offices and back to the suppliers as a means to remove barriers related to culture.

A second, more theoretically oriented, implication of this research is that the paradox theory may help to identify and emphasize inconsistencies among different research fields in a structured manner. This is particularly valuable for research areas built upon multiple research disciplines such as global sourcing. For instance, from the literature review presented in this research, what constitutes learning and development in the supply chain is clearly viewed very differently in different research fields. Whereas traditional logistics literature advocates long term relationships as a cornerstone for learning and development, economic geography instead promotes a change of suppliers as a major trigger. Another example is the inconsistency between logistics-related research on performance measurements on the one hand, and environmental research on the other. Whereas the first area is focused around traditional logistics parameters such as cost and service, the latter is concerned with environmental issues in which (sometimes) no consideration on logistics performance is taken.

In a wider sense, the paradox theory supports a new era of research where previous contingency-based research is downplayed in favour of a more dynamic view of organisational research (Graetz and Smith, 2009; Dameron and Torset, 2014). In this research, organisational design does not become a question of finding an optimal, final design, but rather the continuous balancing of tensions inherent in the organisation. This development goes hand in hand with recent research in strategic management, where dynamic capabilities theory has been developed from the more static resourcebased view of the firm (Pavlou and El Sawy, 2011). For logistics and SCM researchers, the development in organisational as well as strategic management theory signals the need for new theoretical lenses where dynamism and change could be managed and understood also in a logistics and SCM context. The paradox theory, which has been elaborated in this paper, is one answer to this call. Being informed about the paradoxes present in the organisation may work as a catalyst and foundation towards more effective change management processes.

This explorative research suffers from several limitations; in particular these are related to the case study approach chosen. The two case studies presented have had the role of exemplifying paradoxes inherent in global sourcing practices, rather than developing or 
changing the existing paradox framework applied from Smith and Lewis (2011). With more empirical data at hand, from companies with different contexts such as size, industry, degree of internationalisation, etc., the existing framework could have been further verified and adjusted to a logistics and SCM setting. It is outside the scope of this research, but future research in the area should challenge the existing framework and try to develop more specific logistics-related paradox classes. In this work, other data collection approaches such as surveys, participant observations and longitudinal focus groups would be valuable complementary approaches to interviews. Another limitation of the present research is its focus on global sourcing as a context for introducing the paradox theory to the logistics and SCM research field. Although the intention of the research has been to present paradox theory not only to a global sourcing domain of research, but to logistics and SCM in general, there is space for additional explorative studies of paradoxes in other logistics-related research areas.

Beyond future research areas originating from the limitations of this paper, the findings also suggest a number of other potential research themes. One such research theme deals with the need for more knowledge about strategies conducted for the effective handling of paradoxes. Although not the primary focus of the empirical data collection, it revealed a number of strategies for the handling of paradoxes in the area of global sourcing. Some of the most prominent strategies are:

- Product segmentation: A performing paradox is handled (achievement of low costs and short lead times) through a product segmentation where different sourcing strategies are accomplished in different product segments.

- Multiple sourcing in Asia: A learning paradox is handled through the use of several suppliers for the same products. This strategy enables benchmarking activities and a high learning and development pace, meanwhile stability and long term relationships can be fostered in cases when needed.

- Combination of European and Asian suppliers: A performing paradox is handled through a combination of European and Asian suppliers for a certain product, in order to divide "base" and "surge" demand (Christopher et al., 2006). This strategy enables a combination of low cost and flexibility in terms of reduced lead times.

- Supply chain transparency: A belonging paradox is handled through actions undertaken to increase information transparency in the supply chain. Such a transparency is crucial in order to gain intermediaries' loyalty towards headquarters and at the same time avoid them becoming barriers in terms of e.g. information exchange.

These strategies are well known in existing global sourcing research, but have so far not been considered from a paradox perspective. This research suggests that it is possible to view paradoxes as significant drivers for conducting these strategies, i.e. the reason for launching these strategies could be to handle one or several paradoxes inherent in the organisation. More insights into the motives for launching a certain strategy, as well as the evaluation of alternative strategies (from a paradox point of view) would be valuable for future research.

A second potential future research theme is the managerial use of a paradox perspective in a logistics and SCM environment. The interviews revealed that the full exploitation of paradoxes as a driving force for development and change in the company is a demanding challenge for management. In general, paradox literature assumes that a 
cognitive capability among management and scholars is needed to understand and handle the paradoxes successfully (Dameron and Torset, 2014). More research about this capability is needed. For instance, the findings from this research indicate that the cognitive capability of managers to apply systems thinking in their practice is crucial in a global sourcing environment. In particular the ability to rapidly change analytical unit from parts to entirety and then back again is decisive. Several of the interviewees addressed management of paradoxes as a challenge of thinking as other individuals and members of the supply chain, and at the same time not lose the "whole picture". This type of cognitive capability is probably not only valid in a global sourcing setting, but in the logistics and SCM environment in general. Future research may identify and suggest other such more specific cognitive capabilities that are needed in a logistics and SCM context.

\section{References}

Aastrup, J., D. Grant, and M. Bjerre 2007. "Value creation and category management through retailer-supplier relationships." International Review of Retail, Distribution and Consumer Research 17 (5): 523-541.

Agrawal, N., S. Smith, and A. Tsay 2002. "Multi-vendor sourcing in a retail supply chain." International Journal of Production and Operations Management 11 (2): 157-182.

Åkesson, J., P. Jonsson and R. Edanius-Hallås 2007. "An assessment of sourcing strategies in the Swedish apparel industry." International Journal of Physical Distribution \& Logistics Management 37 (9): 740-762.

Bakal, I. and J. Geunes 2010. “Order timing strategies in a single-supplier, multi-retailer system.” International Journal of Production Research 48 (8): 2395-2412.

Brito, M., V. Carbone and C.M. Blanquart, 2008. "Towards a sustainable fashion retail supply chain in Europe: Organisation and performance." International Journal of Production Economics 114 (2): 534-553.

Bygballe, L., B. Eirill and S.E. Grönland 2012. "Managing international supply: The balance between total costs and customer service." Industrial Marketing Management 41 (3): 394-401.

Cho, J.E. 2009. "When does it make sense for US retailers to opt for backward integration for global sourcing?" International Journal of Retail \& Distribution Management 37 (3): 271-285.

Cho, J. and J. Kang 2001. "Benefits and challenges of global sourcing: perceptions of US apparel retail firms." International Marketing Review 18 (5): 542-561.

Christopher, M., H. Peck, and D. Towill 2006. "A taxonomy for selecting global supply chain strategies." International Journal of Logistics Management 17 (2): 277-287.

Dameron, S. and C. Torset 2014. "The discursive construction of strategists' subjectives: Towards a paradox lens on strategy." Journal of Management Studies 51 (2): 291-319.

Defee, C.C., B. Williams, W.S. Randall, and R. Thomas 2010. "An inventory of theory in logistics and SCM research." International Journal of Logistics Management 21 (3): 404489. 
Eisenhardt, K. and M. Graebner 2007. "Theory Building From Cases: Opportunities and Challenges." Academy of Management Journal 50 (1): 25-32.

Eisenhardt, K. 2000. "Paradox, spirals, ambivalence: the new language of change and pluralism." Academy of Management Review 25 (4): 703-705.

Evans, P., V. Pucik and I. Björkman 2002. The global challenge. second ed. McGraw-Hill International Edition, ISBN 978-0-07-111417-2.

Fawcett, S., M. Waller, J. Miller, M. Schwieterman, B. Hazen, and R. Overstreet 2014. "A trail guide to publishing success: Tips on writing influential conceptual, qualitative and Survey research." Journal of Business Logistics 35 (1): 1-16.

Flyvbjerg, B. 2006. "Five misunderstandings about case study research." Qualitative Inquiry 12 (2): 219-45.

Galunic, D. and K. Eisenhardt 2001. "Architectural innovation and modular corporate forms." Academy of Management Journal 44 (6): 1229-1249.

Ganesan, S., M. George S. Jap, R.W. Palmatier and B. Weitz 2009. "Supply chain management and retailer performance: emerging trends, issues, and implications for research and practice." Journal of Retailing 85 (1): 84-94.

Gelderman, C. and J. Semeijn, 2006. "Managing the global supply base through purchasing portfolio management." Journal of purchasing \& Supply Management 12: 209217.

Gibbon, P. 2002. "At the cutting edge? Financialisation and UK clothing retailers' global sourcing patterns and practices." Competition and Change 6(3): 289-309.

Graetz, F. and A. Smith 2009. "Duality Theory and Organizing Forms in Change Management.", Journal of Change Management 9 (1): 9-25.

Halldorsson, A., H. Kotzab, J.H. Mikkola, and T. Skjoett-Larsen 2007. "Complementary theories to supply chain management." Supply Chain Management: An International Journal 12 (4): 284-296.

Halldorsson, A., J. Hsuan and H. Kotzab 2015. "Complementary theories to supply chain management revisited - from borrowing theories to theorizing." Supply Chain Management: An International Journal 20 (6): 574-586.

Handy, C. 1994. The age of paradox. Cambridge, MA: Harvard Business School Press

Hughes, A., M. Buttle, and N. Wrigley 2007. "Organisational geographies of corporate responsibility: a UK-US comparison of retailers' ethical trading initiatives." Journal of Economic Geography 7 (4): 491-513.

Jonsson, A and D. Tolstoy 2014. "A thematic analysis of research on global sourcing and international purchasing in retail firms." International Journal of Retail and Distribution Management 42(1): 56-83.

Joo, S.-J., H. Min, I.-W. Kwon, and H. Kwon 2010. "Comparative efficiencies of specialty coffee retailers from the perspectives of socially responsible global sourcing." International Journal of Logistics Management 21 (3): 490-509.

Kotabe, M. and J. Murray 2004. "Global procurement of service activities by service firms." International Marketing Review 21 (6): 615-633. 
Lewis, M. 2000. "Exploring paradox: Toward a more comprehensive guide." Academy of Management Review 25 (4): 760-776.

Lowson, R. 2001. "Offshore sourcing: An optimal operational strategy?" Business Horizon 6: 61-66.

Luscher, L. and M. Lewis 2008. "Organizational change and managerial sensemaking: working through paradox." Academy of Management Journal 51 (2): 221-240.

Mamic, I. 2005. "Managing global supply chain: The sports footwear, apparel and retail sectors." Journal of Business Ethics 59 (1/2): 81-100.

Mentzer, J.T., W. DeWitt, J.S. Keebler, S. Min, N.W. Nix, C.D. Smith and A.G. Zacharia. 2001. "Defining Supply Chain Management." Journal of Business Logistics 22 (2): 1-25.

Mena, C., A. Humphries, and R. Wilding 2009 "A comparison of inter- and intraorganizational relationships.", International Journal of Physical Distribution and Logistics Management 39 (9): 762-784.

Monczka, R. M., R.B. Handfield, L.C. Giunipero, J.L. Patterson, and D. Waters 2010. Purchasing and supply chain management. Andover: South-Western Cengage Learning.

Nosella, A., S. Cantarello and R. Filippini 2012. "The intellectual structure of organizational ambidexterity: A bibliographic investigation into the state of the art." Strategic organisation 10 (4): 450-465.

Paché, G. 1998. "A transactional approach to global sourcing: application to French food retailers." International Journal of Retail \& Distribution Management 26 (2): 88-96.

Paré, G, M-C. Trudel, M. Jaana and S. Kitsiou 2015. "Synthesizing information systems knowledge: A typology of literature reviews." Information \& Management 52 (2):183199.

Pavlou, P. and O. El Sawy 2011. "Understanding the Elusive Black Box of Dynamic Capabilities.” Decision Sciences Journal 42 (1): 239273.

Perry, P. and N. Towers 2013. "Conceptual framework development: CSR implementation in fashion supply chains." International Journal of Physical Distribution \& Logistics Management 43 (5/6): 478-500.

Poole, M .S., and A. Van de Ven 1989. "Using paradox to build management and organizational theory." Academy of Management Review 14 (4): 562-578.

Pratt, M. 2009. "For the lack of a boilerplate: Tips on writing up (and reviewing) qualitative research." Academy of Management Journal 52 (5): 856-862.

Quintens, L., P. Matthyssens, W. Faes 2005. "Purchasing on both sides of the Atlantic." Journal of Purchasing and Supply Management 11 (1): 57-71.

Robinson, P. 2010. "Responsible retailing: The practice of CSR in Banana plantations in Costa Rica." Journal of Business Ethics 91: 279-289.

Seo, M.-G., L. Putnam and J.M. Bartunek 2004. "Dualities and tensions of planned organizational change.", In S. Poole \& A. Van de Ven (Eds.), Handbook of organizational change, pp. 73-107. Oxford: Oxford University Press.

Smith, W. and M. Lewis, 2011. "Toward a theory of paradox: A dynamic equilibrium model of organizing." Academy of Management Review 36 (2): 381-403. 
Stock, G., N. Greis, and J. Kasarda, 1998. "Logistics, strategy and structure." International Journal of Operations \& Production Management 18 (1): 37-52.

Stock, J. 1997. "Applying theories from other disciplines to logistics." International Journal of Physical Distribution and Logistics Management 27 (9/10): 515-539.

Toklati, N. 2008. "Global sourcing: insights from the global clothing industry - the case of Zara, a fast fashion retailer." Journal of Economic Geography 8 (1): 21-38.

Trautmann, G., L. Bals and E. Hartmann 2009. "Global sourcing in integratednetworkstructures: The case of hybrid purchasing organizations.", Journal of International Management 15 (2): 194-208.

Trent, R. and R. Monczka 2003. "Understanding integrated global sourcing." International Journal of Physical Distribution \& Logistics Management 33 (7): 607-62.

Trent, R. and R: Monczka 2005. "Achieving Excellence in global sourcing.", MIT Sloan Management Review 47 (1): 23-31.

Yin, R.K., 2003. Case Study Research: Design and Methods. Sage Publications. 